\title{
Effect of serotonin in migraine patients
}

\author{
Robert W. Kimball, M.D., Arnold P. Friedman, M.D., \\ and Edward Vallejo, M.D.
}

LITTLE is known of the factors that predispose to migraine or the biochemical events that initiate the disturbances characteristic of this condition. Earlier studies by Marcussen and Wolff $^{1}$ have shown that an initial phase of vasoconstriction is responsible for the prodromal symptoms, while the pain follows a marked distention of cranial vessels that are temporarily hypotonic. They also have presented certain evidence which presumably indicates that a pain threshold-lowering substance renders the distention of the large arteries painful. ${ }^{2}$ However, alteration in tone, lumen, and pain threshold of the arteries alone cannot explain the complex symptomatology of the migraine attack.

Jimenez Diaz and associates ${ }^{3}$ have indicated that, during the migraine attack, there is a release of a substance more stable than acetylcholine, which they term S.A.C. acetylcholinelike substance. They also conclude that the normal choline acetylate system is different in these patients. Kunkle ${ }^{4}$ also relates this multisystem disturbance to a preponderance of parasympathetic nervous activity as manifested by a release of acetylcholine. An acetylcholine-like substance has been detected in cerebrospinal fluid during some intracranial vascular headaches of migraine type. These and other studies cast light on the nature of the pathophysiology of migraine, yet the primary event in the migraine attack remains undetermined. The effects of serotonin (5hydroxytryptamine-HT) suggest themselves as a means of gaining further understanding of migraine.

The present study undertakes to determine the effects-clinically, physiologically, and biochemically — of serotonin and its precursor, 5-hydroxytryptophane (HTP), on patients with migraine. The physiologic significance of $\mathrm{HT}$ is implied by its potency in the central nervous system, gastrointestinal tract, cardiovascular system, and blood. The cardiovascular phenomena associated with HT excess are particularly interesting, in that its ability to produce vasoconstriction in some instances, and in some instances vasodilation, raises the possibility that this or a similar substance is the trigger, or part of the trigger mechanism, in patients with vascular headaches, that is, migraine. The nervous, cardiovascular, gastrointestinal, and renal effects of HT all have their counterparts in the migraine syndrome. It has been stated by other observers that exogenous HT can elicit an attack of migraine, ${ }^{5}$ and observations with a monoamine oxidase inhibitor have been interpreted to indicate that $\mathrm{HT}$ aggravates the symptoms of migraine. ${ }^{6}$ Wolff and associates ${ }^{7}$ have reported that, in 3 cases, temporal perivascular-injected HT induced effects similar to clinical migraine. This and other clinical studies suggest that a biochemical lesion of fundamental importance exists in migraine.

\section{MATERIALS AND METHODS}

Patients used in this study were a group of 18 females and 17 males between the ages of 24 and 70, all of whom meet our previous criteria for migraine ${ }^{8}$ and are otherwise in good health. They were all studied at the Montefiore Hospital Headache Unit. Complete physical and neurologic examination was done on each patient.

In each subject, the electroencephalogram and pulse wave were recorded before and after intravenous HT and HTP; $5 \mathrm{mg}$. of HT was given over a five-minute period, and vital signs were observed during injection. The dose of

From the Headache Unit, Montefiore Hospital, New York City.

This study was supported in part by the Warner-Chilcott Laboratories Division and in part by the Lucy and Henry L. Moses Foundation.

Read at the eleventh annual meeting of the American Academy of Neurology, Los Angeles, April 18, 1959. 
HTP varied from 10 to $20 \mathrm{mg}$. and was given in a period of one to two minutes. All experiments were controlled with saline injection by means of a double-blind technic.

Having received the $H T$ and HTP, 25 patients received phenelzine in doses of $75 \mathrm{mg}$. per day for one week, in order to increase endogenous HT. Plasma levels of HT were determined in 3 patients after this treatment and in 3 patients with spontaneous headache; these levels were compared to those found in patients without headache and without treatment.

After a week's treatment with phenelzine, 3 subjects received BOL (2-bromo-LSD) in a single intravenous dose of $1.5 \mathrm{mg}$., while 10 received $1.25 \mathrm{mg}$. per day for one week.

After phenelzine, 9 patients received $25 \mathrm{mg}$. of chlorpromazine intravenously; 15 subjects received $2.5 \mathrm{mg}$. of reserpine intramuscularly. Of these, 5 were receiving phenelzine at the time.

Injections of $0.1 \mathrm{mg}$. HT were given to 10 subjects near the temporal artery after induction of $3^{\circ}$ of temperature elevation by means of hot water immersion.

\section{RESULTS}

The symptoms produced by intravenous HT in the migraine subjects were faintness, flushing, and paresthesias. No consistent significant change in pulse, respiration, or blood pressure was observed. Transient dyspnea was observed in all but 4 patients. All symptoms were transient and were more marked in the female than in the male patients. In 4 of the males, no symptoms or objective changes were noted. In no instance did a headache follow

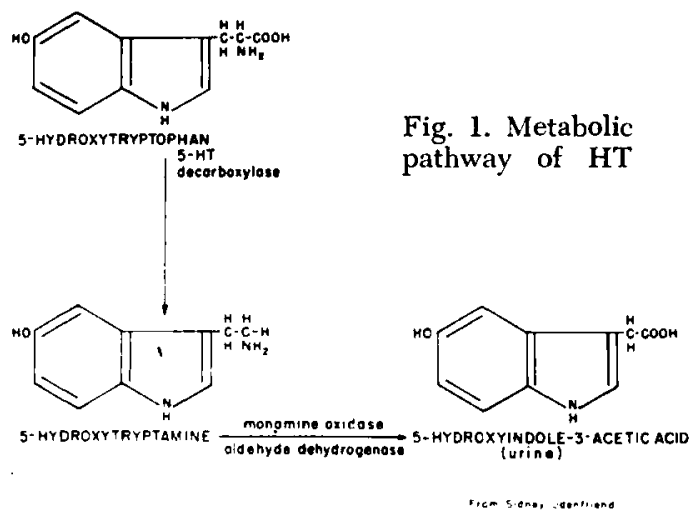

intravenous HT or the paratemporal infiltration of HT. Intravenous HTP in doses as high as $16 \mathrm{mg}$. produced no symptoms whatever.

Electroencephalograms in all subjects were normal, and no change followed intravenous HT or HTP. No characteristic change in amplitude or contour of pulse tracings was observed with either HT or HTP. No significant change in plasma HT was found in the 3 patients with spontaneous headache. An increase in plasma $\mathrm{HT}$ was seen in patients receiving the monoamine oxidase inhibitor, phenelzine. There were no findings to indicate deviation from the usual metabolism of HT (Fig. 1).

In all patients but 1 receiving phenelzine over one-week periods, headaches decreased markedly in severity or frequency. BOL following phenelzine produced no further change in frequency and severity of headaches. Single 25-mg. intravenous doses of chlorpromazine in 9 phenelzine-primed patients produced no effect but somnolence; 10 patients received BOL for periods of one week with a marked improvement of headaches. In 5 patients, spontaneous headaches were relieved with $5 \mathrm{mg}$. of HT intravenously, and, in 3 patients, they were relieved with HTP. HTP also relieved reserpine-induced headaches in 5 cases. Reserpine produced a migraine-like syndrome in 10 patients.

\section{DISCUSSION}

Headache (migraine) is produced in migrainous patients with intramuscular injection of $2.5 \mathrm{mg}$. of reserpine. Headache is not produced by chlorpromazine, another tranquilizer that presumably has a different mode of action. Chlorpromazine does have some sympatholytic effect, which might result in a reduced blood vessel tone.

When reserpine is administered, vasodilation is observed. This could be due to the release of and action of HT or could be a parasympathomimetic effect. In animals, when H'T is infused intravenously rapidly, the blood pressure will rise, and when $\mathrm{HT}$ is infused slowly or when HTP is given, there is a fall in blood pressure. Since the parasympathomimetic effects that follow reserpine are known to continue on chronic dosage, it would be improbable that they are a direct action of HT. These effects could be due to an increase in acetyl- 
choline activity or a relative overplay of acetylcholine based on the reduction of such sympathetic substances as epinephrine, norepinephrine, and HT.

The present studies show that HT and HTP given intravenously do not produce migraine. This would further argue that the reserpine migraine effect is not due to an action of HT. The raising of the endogenous level of HT by the use of a monoamine oxidase inhibitor, phenelzine in this study, does not produce migraine. The administration of $\mathrm{BOL}$ does not invoke or aggravate migraine. It is at least of passing interest that headache has not been reported with the carcinoid syndrome. ${ }^{9-11}$

Rather, HT and/or its precursor HTP, given intravenously, relieve migraine and also relieve the migraine model (reserpine) headache. Also, phenelzine reduces the incidence and severity of migraine attacks. The same is true of BOL.

Virtually no drug has a pure action, and the effects seen in these experiments could be nonspecific ones. However, the substances are all sufficiently closely related chemically so as to share certain pharmacologic actions and certainly to share the ability to attach themselves to the same receptor sites (Fig. 1). An example of this multiplicity of action is phenelzine, which has, on intravenous injection, a sympathomimetic effect similar to such drugs as norepinephrine or amphetamine (also useful in migraine). Phenelzine also produces a sympatholvtic-like effect resulting in postural hypotension. At the same time, the circulating and brain HT increases, and we get a psychicenergizer action, presumably due to the affinity of this substance for monoamine oxidase and the resultant blocking of these receptor sites.

From the current therapy in migraine, we see this same difficulty of multiplicity of effects, since the ergot derivatives are both vasoconstrictor, presumably through a direct muscle action, and adrenolytic or sympatholytic, causing a reversal of epinephrine effects.

It is also possible that more mechanisms than 1 are involved in the provoking of an individual attack and therefore are available as an approach for the treatment of an attack. But, if we assume that the headache produced by reserpine is due to a reduction in HT at a

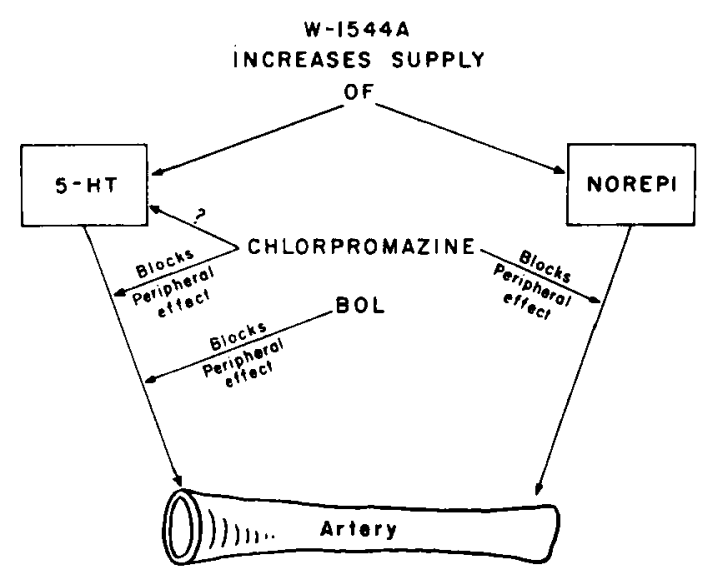

Fig. 2. Schematic representation of blocking agents and their influence on HT and norepinephrine

vascular site, the effect of $\mathrm{HT}$ and its precursor HTP in replacing this would follow and headache relief could be expected. The effect of phenelzine would also be explained, as the monoamine oxidase blockade resulted in a protection of endogenous HT.

One would have some difficulty in explaining the role of BOL on this basis except that, at the site which we may be discussing, it may have the same effect as HT. The anti-HT effect of BOL is usually demonstrated with blood vessels in vitro, and it need not follow that the effect being observed on contraction and relaxation in such a system is the effect that we are studying in migraine. It is highly unlikely that $\mathrm{BOL}$ is a pure pharmacologic entity and that it does not have some of the same actions that both phenelzine and HT show (Fig. 2).

This situation is further complicated by the possibility that all of these substances are acting in the central nervous system and not at the vessel site, since they are all known to have such effects. Even HTP has been shown to be capable of producing hallucinations when administered in large quantities. ${ }^{12}$

The ameliorating effect attending increased endogenous serotonin is unaffected by the peripheral blocking action of BOL. This observation can be interpreted as evidence against the peripheral site. That the serotonin effect and release of acteylcholine are independent events is suggested by the relief of 


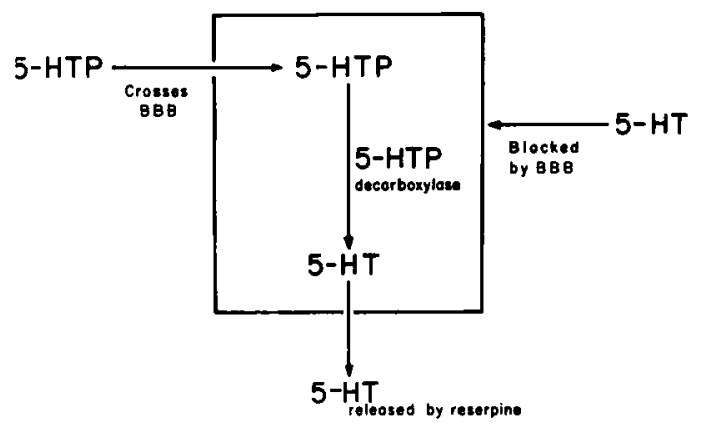

Fig. 3. Diagram depicting HT and 5-HTP and their penetrability of blood-brain barrier (BBB)
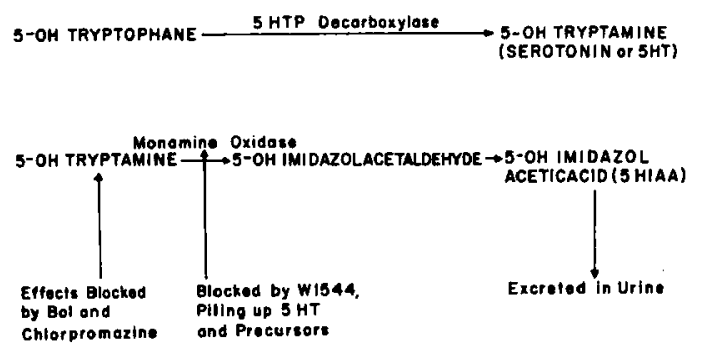

Fig. 4. Effect of phenelzine (W-1544) on HT metabolism

DI-OH PHENYLALANINE $\stackrel{\text { DOPO Docarboxylase }}{\longrightarrow}$ NOR-EPINEPHRINE

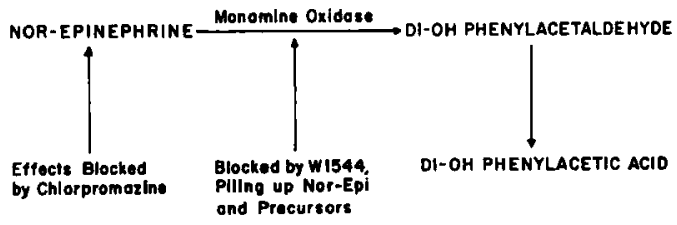

Fig. 5. Effect of phenelzine (W-1544) on norepinephrine metabolism

headache by HTP without interrupting pronounced vagal effects, for instance flushing.

Separation of peripheral and central effects depends on the impermeability of blood-brain barrier to HT and the permeability to HTP. The mechanism whereby HT exerts its central nervous system influence has been partially adumbrated by the study of reserpine's effect on the central nervous system. Reserpine depletes the brain of serotonin and produces cer- tain pharmacologic effects, for example, prolongation of sedation. Whether these effects of reserpine are caused by free serotonin or by its absence from the brain cells is not certain. The explanation that reserpine's effects are due to free serotonin assumes that small amounts of serotonin cross the blood-brain barrier. ${ }^{13} \mathrm{On}$ this point there is a degree of uncertainty. That some serotonin could cross the bloodbrain barrier offers no hardship to the interpretation of our results and, in fact, could account for the improvement in spontaneous headache observed to follow intravenous HT (Fig. 3).

While there is evidence to support the view that depletion of HT and migraine are related, difficulty arises in attributing the ameliorating effects of phenelzine solely to the attendant rise in HT. The effect of the phenelzine molecule itself has been neglected, and further observations are necessary in order to determine the effect of amines, other than HT, that accumulate as a result of monoamine oxidase inhibition (Figs. 4 and 5).

A number of points remain to be elucidated, among which is the peripheral effect of reserpine. In the absence of strong supporting evidence for peripheral action of $\mathrm{HT}$ in migraine, the reproducibility of migraine by HT depletion can be considered a useful hypothesis for further study of the migraine problem.

\section{SUMMARY}

1. Neither HT nor HTP has induced migraine by intravenous administration in 35 cases. Subcutaneous paratemporal arterial injections of HT in 25 cases failed to produce symptoms of migraine.

2. Increase in endogenous serotonin by means of phenelzine, a monoamine oxidase inhibitor, did not provoke migraine.

3. Peripheral block of serotomin by BOL has not provoked migraine.

4. HT and HTP did not produce electroencephalographic changes in 35 cases of $\mathrm{mi}$ graine with normal tracings.

5. Reserpine (2.5 mg. intramuscularly) induced typical migraine headache in 9 of 10 patients by a mechanism remaining to be clarified.

6. Phenelzine, a monoamine oxidase inhibitor, given over a short period of time in this 
series, has markedly reduced the frequency and severity of migraine.

7. BOL given over a short period of time in this series has markedly reduced the frequency and severity of migraine.

8. HT has abolished spontaneous migraine headaches. HTP has abolished both spontaneous migraine and reserpine-induced headaches.

9. In 3 instances of spontaneous migraine, the plasma level of HT was found to be not remarkably altered.

10. Possible mechanisms of migraine and the role of serotonin are discussed.

The authors wish to thank Drs. William Govier, Saul Korey, and Joseph White for their advice and suggestions and Mrs. Elsie Kathman for her assistance in carrying out this research project.

Phenelzine was supplied by Warner-Chilcott Laboratories Division as Nardil; BOL was supplied by Sandoz Pharmaceutical Division.

\section{REFERENCES}

1. Marcussen, R. M., and WolfF, H. G.: Studies on headache. Arch. Neurol. \& Psychiat. 63:41, 1950.

2. WolfF, H. G., Tunis, M. M. and Goodell, H.: Evidence of tissue damage and changes in pain sensitivity in subjects with vascular headaches of the migraine type. Arch. Int. Med. 92:478, 1953.

3. Jimenez Diaz, C., Lonente Fernandez, L., Marcos Lanzarot, M., and Ortega, A.: Observations on the nature and physiopathology of migraine. Internat. Arch. Allergy 7:356, 1955 .

4. KunkLe, R. C.: Acetylcholine in the mechanism of headaches of migraine type. Arch. Neurol. \& Psychiat. $81: 135,1959$.

5. OstFELD, A. M.: Newer knowledge of non-migrainous headaches. Address given at American Society of Angiology, San Francisco, 1958.

6. SAINZ, A.: Unpublished observations, Marcy Hospital, 1958.

7. Wolff, H. G., Ostreld, A. M., Chapman, L. F., and GoODELl, H.: Studies in headache: A summary of evidence implicating a locally active chemical agent in migraine. Tr. Am. Neurol. A., 81st meeting, 1956. p. 356

8. Friedman, A. P.: Modern Headache Therapy. St. Louis, C. V. Mosby, 1951. pp.105-106

9. MACDonald, R. A.: A study of 356 carcinoids of the gastrointestinal tract. Am. J. Med. 21:867, 1956.

10. Sjoerdsma, A., Weissbach, H., and Udenfriend, S.: $A$ clinical, physiologic and biochemical study of patients with malignant carcinoid (argentaffinoma). Am. J. Med. 20:520, 1956.

11. Sjoerdsma, A., Weissbaci, H., Terry, L. L., and UDENFruend, S.: Further observations on patients with malignant carcinoid. Am. J. Med. 23:5, 1957.

12. Davidson, J. D., Sjoerdsma, A., Loomis, L. N., and UDENFRIEND, S.: The effects of 5-HTP, the precursor of HT in experimental animals and man. Clin. Res. Proc. 5:304, 1957.

13. Bhodre, B. B.: Storage and release of 5-hydroxytryptamine. In G. P. Lewis, ed.: 5-Hydroxytryptamine. New York, Pergamon Press, 1958. p. 74 


\section{Neurology}

Effect of serotonin in migraine patients

Robert W. Kimball, Arnold P. Friedman and Edward Vallejo

Neurology 1960;10;107

DOI 10.1212/WNL.10.2.107

This information is current as of February 1, 1960

\begin{tabular}{|c|c|}
\hline $\begin{array}{l}\text { Updated Information \& } \\
\text { Services }\end{array}$ & $\begin{array}{l}\text { including high resolution figures, can be } \\
\text { found at: } \\
\text { http://n.neurology.org/content/10/2/107. } \\
\text { citation.full }\end{array}$ \\
\hline Citations & $\begin{array}{l}\text { This article has been cited by } 1 \\
\text { HighWire-hosted articles: } \\
\text { http://n.neurology.org/content/10/2/107. } \\
\text { citation.full\#\#otherarticles }\end{array}$ \\
\hline Permissions \& Licensing & $\begin{array}{l}\text { Information about reproducing this } \\
\text { article in parts (figures,tables) or in its } \\
\text { entirety can be found online at: } \\
\text { http://www.neurology.org/about/about_ } \\
\text { the_journal\#permissions }\end{array}$ \\
\hline Reprints & $\begin{array}{l}\text { Information about ordering reprints can } \\
\text { be found online: } \\
\text { http://n.neurology.org/subscribers/adver } \\
\text { tise }\end{array}$ \\
\hline
\end{tabular}

Neurology ${ }^{\circledR}$ is the official journal of the American Academy of Neurology. Published continuously since 1951, it is now a weekly with 48 issues per year. Copyright $@ 1960$ by the American Academy of Neurology. All rights reserved. Print ISSN: 0028-3878. Online ISSN: 1526-632X.

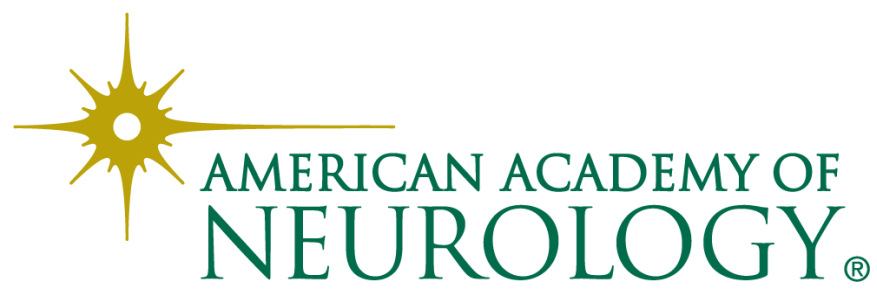

